\title{
AANVULLING OVER 1938 \\ OP DE JAARCIJFERS VAN SURINAME
}

DOOR

L. C. PREY

Teneinde de lezers, die in het bezit zijn van de Jaargangen XXI, XXII en XXIII, waarin de ,Jaarcijfers van Suriname” zijn opgenomen, in staat te stellen deze bij te werken met de cijfers over 1938, zijn deze hieronder in staatvorm opgenomen.

In elke kolom komen de cijfers voor in dezelfde volgorde, waarin zij, in het nummer van den jaargang, dat boven de staten is vermeld, in horizontale richting zijn gesteld. (Zie voorbeeld a.o.z.)

Enkele cijfers zijn in verband met den ingetreden oorlogstoestand, die het verkrijgen van gegevens onmogelijk maakte, niet bekend. Te dezer plaatse zijn in de kolommen de letters: n.b. opgenomen.

De cijfers der „,Middelen en inkomsten” zijn voorloopige. Er hebben daarna nog eenige verrekeningen plaats, zoodat het definitieve cijfer eerst later bekend wordt. Deze definitieve cijfers konden, wegens bovenvermelde redenen, niet worden verkregen. In den regel wijken de definitieve cijfers echter weinig van de voorloopige af.

De cijfers in de drie kolommen in Jaargang XXIII No. 2 zijn over de aan 1938 voorafgegane jaren, die, welke in het Slot van Rekening zijn opgenomen. Dit stuk is, wat het dienstjaar 1938 betreft, - mede tengevolge van den oorlogstoestand - nog niet verschenen. In plaats daarvan zijn de cijfers opgenomen, zooals zij in de vastgestelde Surinaamsche begrooting zijn vermeld. Ook deze cijfers zullen later wellicht eenige wijziging behoeven. 


\section{VOORBEELD}

De cijfers uit de eerste kolom op bladzijde 296 kunnen op de hieronder aangegeven wijze in de correspondeerende statistiek wordèn overgenomen.

WEERKUNDIGE WAARNEMINGEN TE PARAMARIBO

EN REGENVAL TE PARAMARIBO EN OP ENKELE ANDERE PLAATSEN

\begin{tabular}{|c|c|c|c|c|c|c|c|c|c|c|c|c|c|c|}
\hline \multirow[t]{2}{*}{ Jaren } & \multicolumn{2}{|c|}{$\begin{array}{l}\text { Luchtdruk } \\
\text { in mm herleid } \\
\text { op } 0^{\circ} \mathrm{C} \text {. }\end{array}$} & \multicolumn{2}{|c|}{$\begin{array}{l}\text { Temperatuur } \\
\text { graden } \mathrm{C} .\end{array}$} & \multicolumn{2}{|c|}{$\begin{array}{l}\text { Dampkring- } \\
\text { drukking } \\
\text { in mm. }\end{array}$} & \multirow{2}{*}{\begin{tabular}{|c|} 
Betrek- \\
kelijke \\
vochtig- \\
heid in \\
$\%$ gem:
\end{tabular}} & \multirow{2}{*}{$\begin{array}{c}\text { Bewol- } \\
\text { king } \\
(0-10) \\
\text { gem. }\end{array}$} & \multicolumn{6}{|c|}{ Totale regenval in $\mathrm{mm}$} \\
\hline & $\max$. & $\min$. & $\max$. & $\min$. & $\max$ & $\min$. & & & $\begin{array}{l}\text { Para- } \\
\text { maribo }\end{array}$ & $\begin{array}{l}\text { Repu- } \\
\text { bliek }\end{array}$ & $\begin{array}{c}\text { Browns- } \\
\text { weg }\end{array}$ & $\begin{array}{l}\text { Alli- } \\
\text { ance }\end{array}$ & $\begin{array}{c}\text { Coro- } \\
\text { nie }\end{array}$ & $\begin{array}{l}\text { Nicke- } \\
\text { rie }\end{array}$ \\
\hline 1938 & 764.1 & 756.7 & 35.7 & 20.0 & 25.5 & 14.0 & $81 .-$ & 6.1. & 2715.4 & 2380.3 & 2534.1 & 3085.0 & 2933.2 & 2668.9 \\
\hline
\end{tabular}


JAARCIJFERS VAN SURINAME 1938

\begin{tabular}{|c|c|c|c|c|c|c|c|c|c|c|c|c|}
\hline & Jaa & rrgang $X$ & XI. No. & & & & Jaa & rgang $\mathrm{X}$ & XI. No & & & \\
\hline 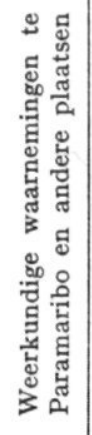 & 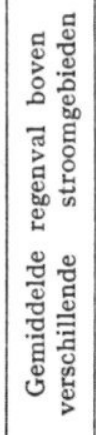 & 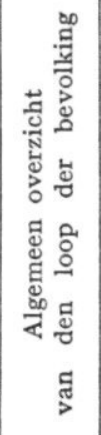 & 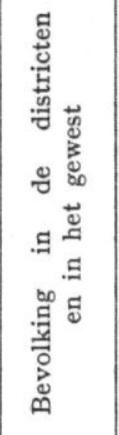 & 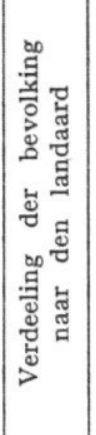 & 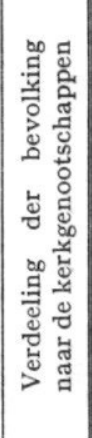 & 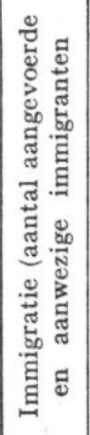 & 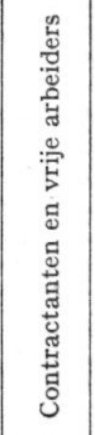 & 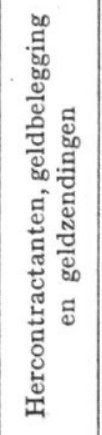 & 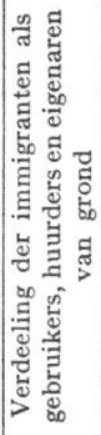 & 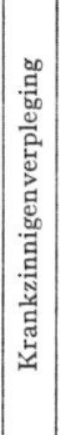 & 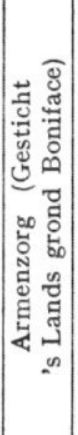 & (ü \\
\hline 764.1 & 2780.0 & 152.589 & 52.760 & 624 & 8.773 & - & - & - & 517 & 1 & 270 & \\
\hline 756.7 & 2954.7 & 646 & 42.839 & 387 & 3.915 & - & - & - & 56 & 150 & 133 & \\
\hline 35.7 & 2647.9 & 483 & 25.646 & 654 & 29.575 & - & - & - & 676 & 147 & - & \\
\hline 20.0 & 2407.9 & 475 & 3.517 & 352 & 30.277 & 11 & - & - & 3.351 & 50 & 403 & \\
\hline 25.5 & 2593.8 & 958 & 4.027 & 31.968 & 799 & 2 & - & 7.742 & 2.745 & 52 & 218 & \\
\hline 14.0 & 2873.7 & 1.785 & 14.994 & 36.587 & 66 & 13 & 3.905 & 131.612 & 9.236 & 0 & 127 & \\
\hline 81.- & 2913.4 & 1.771 & 8.806 & 23.338 & 357 & - & 3.181 & 5.950 & 951 & 0 & 51 & \\
\hline 6.1 & & 3.556 & - & 21.136 & 527 & - & 1.861 & 24.365 & 2.595 & 20 & 3 & \\
\hline 2715.4 & & 4.514 & 152.589 & 17.491 & 41.475 & - & 1.689 & - & 6.502 & 13 & 4 & \\
\hline 2380.3 & & 42 & \pm 19.000 & 14.632 & 32.160 & 23.338 & 10.636 & 5.700 & 1.870 & 13 & 403 & \\
\hline 2534.1 & & 204 & \pm 2.600 & 1.642 & 1.300 & 21.136 & - & & 3.124 & 15 & 60 & \\
\hline 3085.0 & & 242 & & 528 & 3.365 & 44.474 & - & & - & 17 & 2 & \\
\hline 2933.2 & & 1.916 & & 1.876 & & 17.491 & - & & 243 & 15 & 62 & \\
\hline 2668.9 & & 2.598 & & 1.374 & & 14.632 & - & & 4.255 & 150 & - & \\
\hline & & n.b. & & & & 32.123 & $-\overline{608}$ & & 22.345 & 156 & $\begin{array}{l}67 \\
30\end{array}$ & \\
\hline & & & & & & & $\begin{array}{l}608 \\
420\end{array}$ & & & & - & \\
\hline & & & & & & & $\begin{array}{l}407 \\
357\end{array}$ & & & & $\begin{array}{r}97 \\
1\end{array}$ & \\
\hline & & & & & & & 17.92 & & & & 31 & \\
\hline & & & & & & & & & & & 142 & \\
\hline & & & & & & & & & & & $\begin{array}{r}205 \\
24\end{array}$ & \\
\hline & & & & & & & & & & & 403 & \\
\hline & & & & & & & & & & & & \\
\hline & & & & & & & & & & & & \\
\hline & & & & & & & & & & & & \\
\hline & & & & & & & & & & & & \\
\hline & & & & & & & & & & & & \\
\hline & & & & & & & & & & & & \\
\hline
\end{tabular}




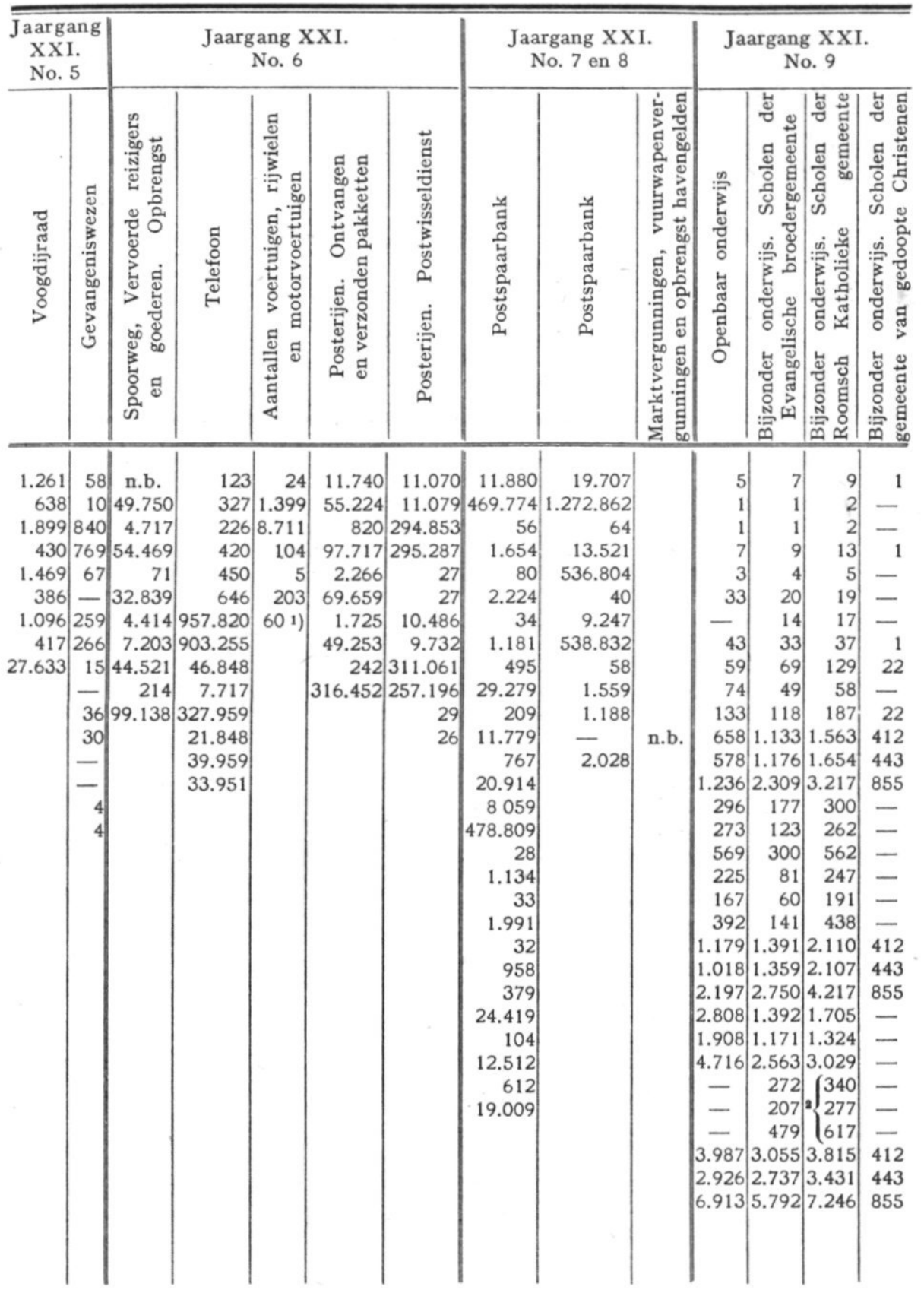

1) Cijfer over 1937 moet niet zijn 18, maar 48.

2) Overeenkomstige cijfeors vor 1937 moeten zijn: 342, 377 en 619 . 


\begin{tabular}{|c|c|c|c|c|c|c|c|}
\hline \multicolumn{3}{|c|}{ Jaargang XXI. No. 10} & \multicolumn{5}{|c|}{ Jaargang XXI. No. 12} \\
\hline 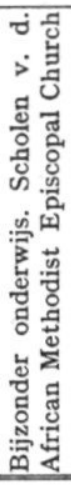 & 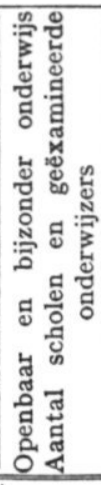 & 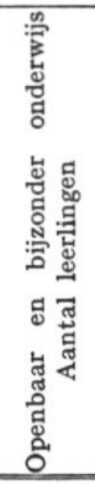 & 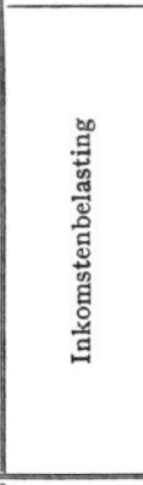 & 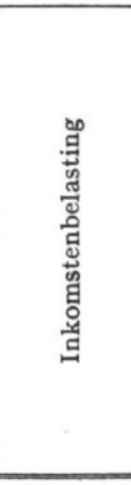 & 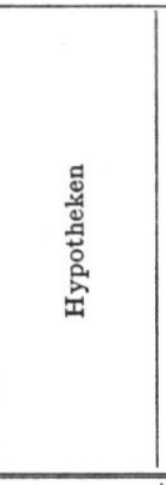 & 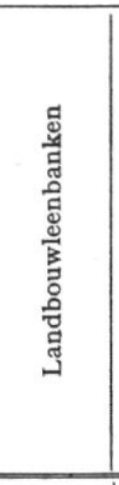 & 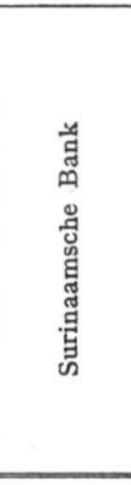 \\
\hline 2 & 24 & 3.985 & 5.823 & 29 & $3902)$ & 62) & 1.129 .466 \\
\hline - & 4 & 4.089 & 8.560 .540 & 1.912 .700 & $779.810^{\prime}$ & 3.462 & 1.908 .109 \\
\hline - & 4 & 8.074 & 8.069 & 191.270 & 434 & 6 & 261.900 \\
\hline 2 & 32 & 773 & 8. 076.400 & 6.595 & 1.103 .858 & 150 & 44.08 \\
\hline- & 12 & 658 & 229.026 & 34 & 3.250 & 682 & 834.333 \\
\hline 1 & 73 & 1.431 & 39.32 & 161.800 & 10.255 .720 & 21.137 & 795.912 \\
\hline- & 31 & 553 & 252 & 16.180 & & 638 & 78.574 \\
\hline 3 & 85 & 418 & 500.260 & 476 & . & 23.444 & \\
\hline 10 & 117 & 971 & - & & & 21.072 & \\
\hline 3 & 289 & 5.950 & 500.260 & & & 11.208 & \\
\hline 13 & 184 & 4.418 & 13.215 & & & 3.483 & \\
\hline 219 & 473 & 10.368 & 52.44 & & & 43.812 & \\
\hline 238 & & 612 & & & & 2.499 & \\
\hline 457 & & 484 & & & & & \\
\hline - & & 1.096 & & & & & \\
\hline - & & 2.197 & & & & & \\
\hline - & & 2.750 & & & & & \\
\hline- & & 4.217 & & & & & \\
\hline- & & 855 & & & & & \\
\hline$\overline{219}$ & & $\begin{array}{r}457 \\
4,716\end{array}$ & & & & & \\
\hline 238 & & 2.563 & & & & & \\
\hline 457 & & 3.029 & & & & & \\
\hline 45 & & - & & & & & \\
\hline 15 & & & & & & & \\
\hline 60 & & 11.261 & & & & & \\
\hline- & & 9.583 & & & & & \\
\hline$\overline{-}$ & & 20.844 & & & & & \\
\hline$\overline{264}$ & & & & & & & \\
\hline 253 & & & & & & & \\
\hline 517 & & & & & & & \\
\hline & & & & & & & \\
\hline
\end{tabular}

2) waaronder 3 , tot een bedrag van $f 31.879$ wegens bedrijfsverband 
AANVULLING OP DE JAARCIJFERS VAN SURINAME

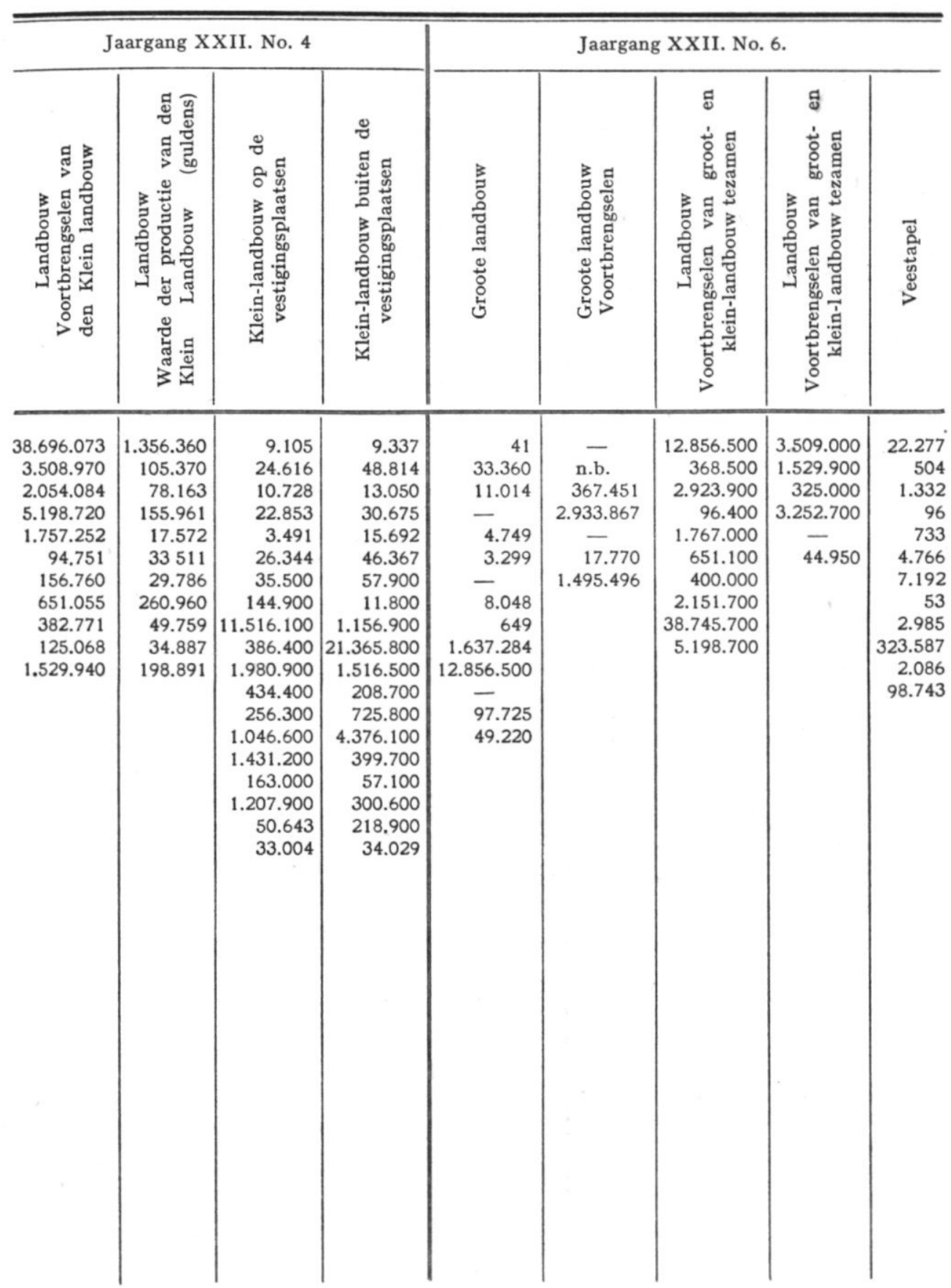




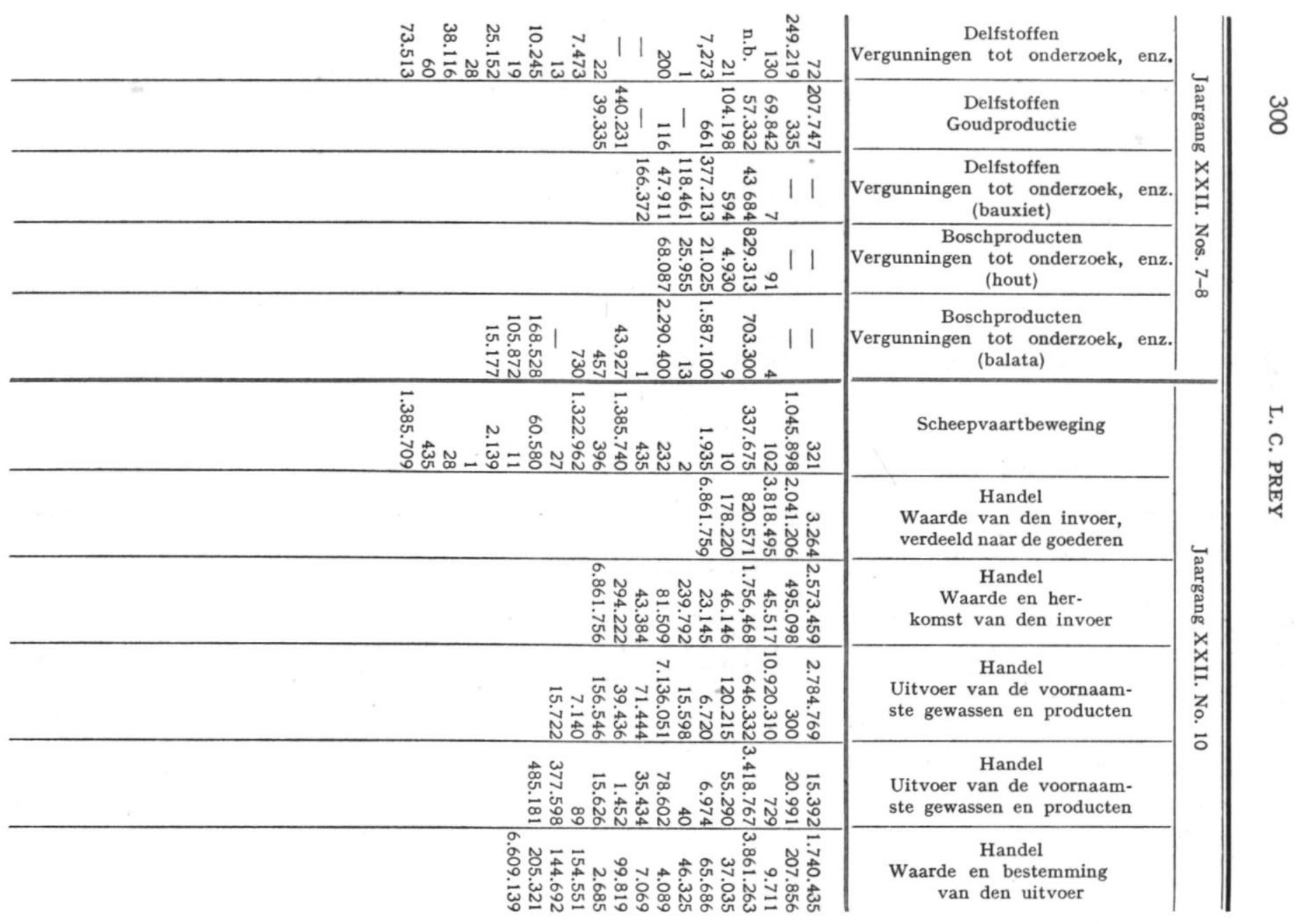




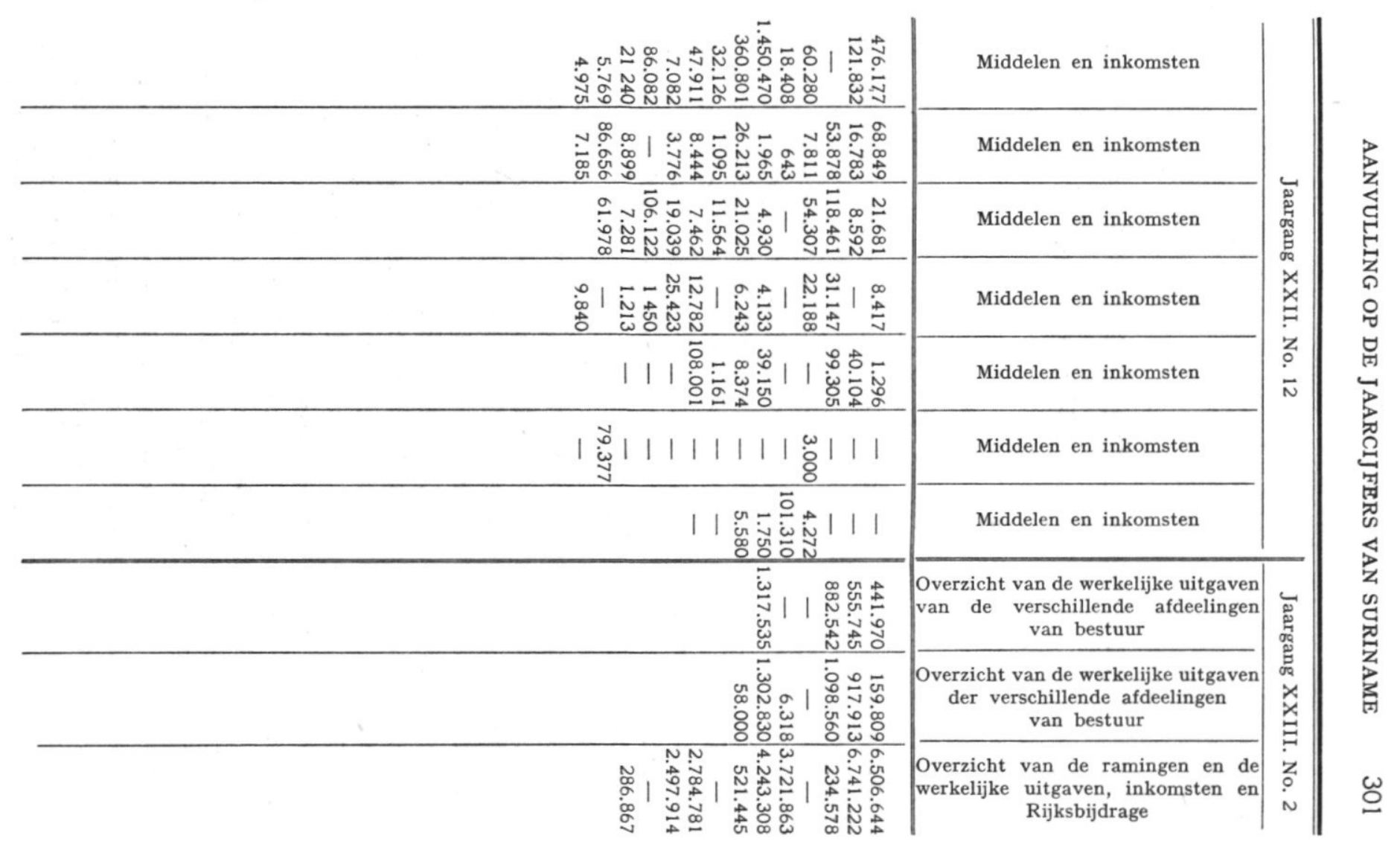

